\title{
Determining the Incidence Rate and Risk Factors of Brucellosis in Zanjan Province (Iran) from 2012 to 2017: A Spatiotemporal Analysis
}

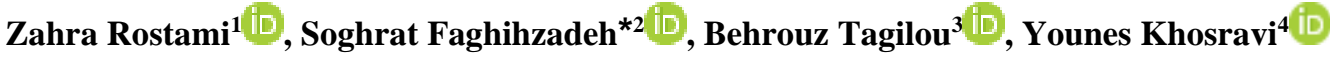

1. Student Research Committee, School of Medicine, Zanjan University of Medical Sciences, Zanjan, Iran

2. Dept. of Biostatistics and Epidemiology, School of Medicine, Zanjan University of Medical Sciences, Zanjan, Iran

3. Dept. of Entomology, School of Medicine, Zanjan University of Medical Sciences, Zanjan, Iran

4. Dept. of Environmental Sciences, School of Sciences, University of Zanjan, Zanjan, Iran

\begin{tabular}{|c|c|}
\hline Article Info & ABSTRACT \\
\hline dof $10.30699 /$ jambs.28.130.247 & \multirow{2}{*}{$\begin{array}{l}\text { Background \& Objective: Zanjan is reported as a hotspot region of brucellosis } \\
\text { infection in Iran. This longitudinal study aimed to determine the epidemiologic } \\
\text { pattern, as well as the risk of brucellosis by using geospatial estimation in Zanjan } \\
\text { province. }\end{array}$} \\
\hline $\begin{array}{l}\text { Received: 2019/09/06; } \\
\text { Accepted: 2020/09/16; }\end{array}$ & \\
\hline Published Online: 21 Sep 2020; & \multirow{2}{*}{$\begin{array}{l}\text { Materials \& Methods: The data used in this study were collected from health centers } \\
\text { in Zanjan province from } 2012 \text { to } 2017 \text { after obtaining the approval of the Committee } \\
\text { of Fighting Infectious Diseases. This longitudinal study was used to determine the } \\
\text { annual pattern of the disease and identify high-risk areas using Moran's statistics, and } \\
\text { then was analyzed using the spatiotemporal Cox model. }\end{array}$} \\
\hline $\begin{array}{l}\text { Use your device to scan and read the } \\
\text { article online }\end{array}$ & \\
\hline (1) & \multirow[t]{2}{*}{$\begin{array}{l}\text { Results: This research showed that the number of affected people in the province } \\
\text { was increased after } 2012 \text {, and the maximum number was observed from } 2013 \text { to } 2014 \text {. } \\
\text { However, from } 2015 \text { to } 2016 \text {, there was a significant decrease. Spatial variations } \\
\text { showed that the incidence of the disease increased in all areas over these six years. } \\
\text { The temporal variations indicated that, from } 2012 \text { to } 2017 \text {, the incidence of brucellosis } \\
\text { in spring and summer was higher than in other seasons; thereafter, the incidence peak } \\
\text { was witnessed in June, July, and August. }\end{array}$} \\
\hline Corresponding Information: & \\
\hline $\begin{array}{l}\text { Soghrat Faghihzadeh, } \\
\text { Dept. of Biostatistics and Epidemiology, } \\
\text { School of Medicine, Zanjan University }\end{array}$ & $\begin{array}{l}\text { Conclusion: The results of this study can be used to determine the starting point of } \\
\text { future programs and evaluate their effectiveness. }\end{array}$ \\
\hline $\begin{array}{l}\text { of Medical Sciences, Zanjan, Iran } \\
\text { E-Mail: } \\
\text { s.faghihzadeh@zums.ac.ir }\end{array}$ & Keywords: Brucella infection, Geospatial, Longitudinal, Trend, Iran \\
\hline $\begin{array}{l}\text { Copyright } \odot 2020 \text {, This is a } \\
\text { copy and redistribution of th }\end{array}$ & ss article distributed under \\
\hline
\end{tabular}

\section{Introduction}

Brucellosis is the most common zoonotic disease among humans and animals; it is also known as undulant fever, wavy fever, Malta fever, and Mediterranean fever (1). Brucellosis is caused by the Brucella species of bacteria and presents itself as acute, under acute, and chronic categories. The disease is transmitted through direct or indirect contact between humans and infected animals. It has gained attention from both economic and health prospects because of miscarriages in animals (barrenness), reductions in milk production, and economic losses of infected livestock. In addition, it causes intense side effects in patients, including fever, malaise, weakness, and weight loss. The infected milk and other dairy products from animals are the most widespread source of oral transmission of Brucella (1).

About 500,000 new cases and $14 \times 10^{5}$ deaths are reported by the World Health Organization (WHO) each year; the Mediterranean countries are considered as high-risk regions (2). In Iran, 68,493 cases were reported from 2011 to 2014, with an incidence rate of 38.6 per 100,000 people (3). In addition, Zanjan province is estimated as a region with a high incidence rate (21-30 per 100,000 in 2010). Therefore, health care professionals, mainly those in developing countries, need modern technologies to confront numerous illnesses and deaths in order to be able to study the role of space in generating and spreading infectious diseases. Considering countries' inabilities to restrict the spread of brucellosis and manage it, scientific evaluations to improve our conception of biology and human behavior can lead us to better manage and control the disease.

The brucellosis incidence rate depends on time and region, whereas the different distributions of disease and incidence rates are reported the provinces in Iran $(1,3)$. Studies have estimated spatiotemporal patterns of disease distribution in Iran and throughout the world 
by using different methods (2-5). However, there is no study regarding the brucellosis distribution using these methods in Zanjan province. The autoregressive integrated moving average (ARIMA) model is a widely used model that can use past and present information to predict the future. The ARIMA model $(5,6)$, geographic information systems (GIS), spatial weights empirical Bayes smoothing (7), and scan statistics (8) have been applied to predict spatiotemporal models.

The literature has reported some limitations of these methods, including the false discovery rate due to multiple testing, length of the scan window, and selection of the number of clusters $(9,10)$. Accounting spatial correlations or structured heterogeneity can help assess interactions between time and area to obtain accurate estimates of risk distributions $(11,12)$. Currently, there are no standards to describe the disease in a spatiotemporal way. The present study offers a new approach to tackling the problems identified in the previous studies and attempts to improve the methodology of future studies.

A spatiotemporal estimation of brucellosis incidence rates has not yet been investigated by using this approach in Zanjan province, which is a high-risk region, and there are substantial knowledge gaps regarding its incidence rate. The present study aims to (1) provide a pattern of brucellosis distribution during a six-year period in urban and rural regions of Zanjan province using a mapping analysis model and (2) estimate the trend of brucellosis incidence rates from 2012 to 2018.

\section{Materials and Methods}

This longitudinal study was conducted using confirmed brucellosis cases in Zanjan province from 2012 to 2017 . Zanjan lies $298 \mathrm{~km}$ north-west of Tehran. It has an area of $21,773 \mathrm{~km}^{2}$, includes 430,871 inhabitants, and comprises 71 rural and 44 urban regions. The 2,829 brucellosis infected cases in the province were confirmed by the Health Deputy Department of Zanjan University of Medical Sciences and utilized for analysis. The data used in this study were collected from the health centers of Zanjan province over six years. They were used for the study after gaining the approval of the Committee of Fighting Infectious Diseases.

It was essential to account for the local and temporal autocorrelation patterns in the data analysis to make statistically unbiased estimates of the parameters in the geographical and trend analyses. The spatiotemporal Cox model holds the assumption of variance inflation, in which incidence rates are dependent among times and neighbors. The brucellosis incidence rate was estimated based on the population at risk in each region. The global Moran's I and Anselin Local Moran's I were used to account for autocorrelation patterns across regions. Moran's I was used to estimate the degree of dispersion in space.

In this study, the spatiotemporal model was used per the following formula (13-17).

$$
\Lambda(\mathrm{x}, \mathrm{t})=\lambda(\mathrm{x})(\mathrm{t}) \mathrm{R}(\mathrm{x}, \mathrm{t}) \text {. }
$$

\section{Results}

In total, 2,829 cases of brucellosis were notified from 2012 to 2017, whereas the estimated incidence rate was 44.6 per 100,000 people during the study period. Table 1 shows demographic distribution data concerning brucellosis from 2012 to 2017, separated by cities, areas, gender, and occupations. Figure 1 shows developing spatial patterns and spatial distribution of brucellosis according to the number of patients in Zanjan city using ArcGIS 10.3.

Table 1. Demographic distribution data concerning brucellosis during 2012-2017

\begin{tabular}{|c|c|c|c|c|c|c|c|}
\hline & Region & 2012 & 2013 & 2014 & 2015 & 2016 & 2017 \\
\hline \multirow{9}{*}{ Cities } & Abhar & 7 & 31 & 46 & 32 & 18 & 15 \\
\hline & Ijroud & 12 & 9 & 27 & 48 & 24 & 17 \\
\hline & Khodabande & 162 & 177 & 227 & 195 & 224 & 162 \\
\hline & Khormdare & 16 & 24 & 24 & 28 & 12 & 18 \\
\hline & Zanjan & 46 & 107 & 177 & 120 & 162 & 143 \\
\hline & Tarom & 21 & 22 & 17 & 39 & 22 & 10 \\
\hline & Mahneshan & 13 & 45 & 64 & 107 & 65 & 46 \\
\hline & Soltaniyeh & 0 & 0 & 2 & 19 & 14 & 13 \\
\hline & Total & 277 & 415 & 584 & 588 & 541 & 424 \\
\hline Occupations & Livestock Farmer & 22.59 & 35.31 & 26.03 & 49.09 & 42.96 & 32.55 \\
\hline
\end{tabular}




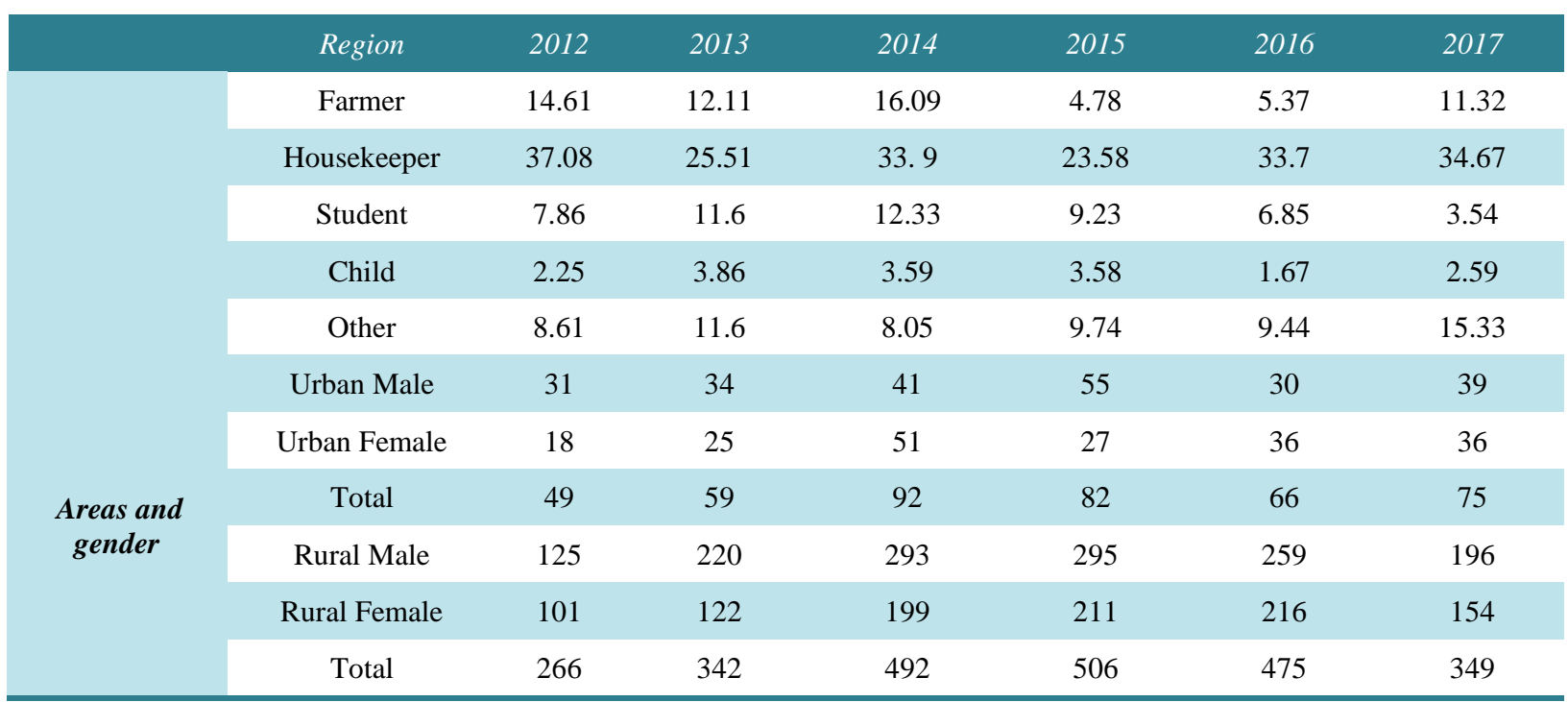

Table 2. Generalized Additive Model (GAM) model for spatial and temporal changes of brucellosis during six years in Zanjan province

\begin{tabular}{|c|c|c|c|c|}
\hline & & Assessment & Confidence interval \% 95 & P-value \\
\hline \multirow{3}{*}{ 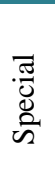 } & $\begin{array}{l}\text { Experience of consuming } \\
\text { unpasteurized dairy products }\end{array}$ & -0.274 & $-45.364 \quad 44815$ & 0.9904 \\
\hline & Occupation & 1.378 & $-5.482 \quad 8.238$ & 0.693 \\
\hline & County & 7.825 & $2.658 \quad 12.993$ & 0.003 \\
\hline \multirow{7}{*}{$\begin{array}{l}\text { 픔 } \\
\stackrel{0}{0} \\
\stackrel{0}{0}\end{array}$} & Area & 15.322 & $-10.585 \quad 41.230$ & 0.246 \\
\hline & Year of record & 215.4 & $1.929 \quad 237.88$ & $2 \mathrm{e}-16$ \\
\hline & $\begin{array}{r}\text { Experience of consuming } \\
\text { unpasteurized dairy product }\end{array}$ & 180.4 & $0.1793 \quad 342.91$ & 0.0296 \\
\hline & Vaccination record of livestock & -754 & $-8.246-683.32$ & $2 e-16$ \\
\hline & Record of touching livestock & -0.288 & -1.4740 .896 & 0.632 \\
\hline & Occupation & -0.216 & $-0.4837 \quad 0.0501$ & 0.111 \\
\hline & Gender & -0.0241 & $-0.7086 \quad 0.660$ & 0.944 \\
\hline
\end{tabular}
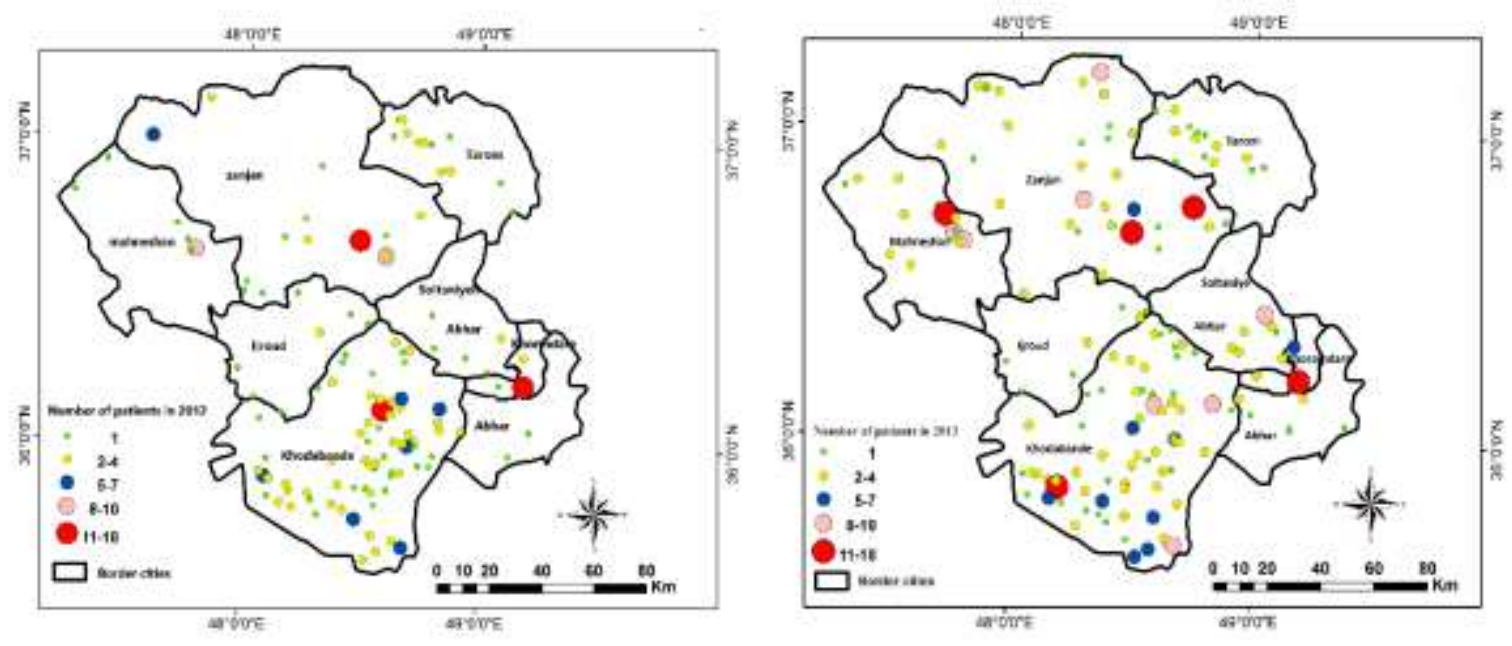

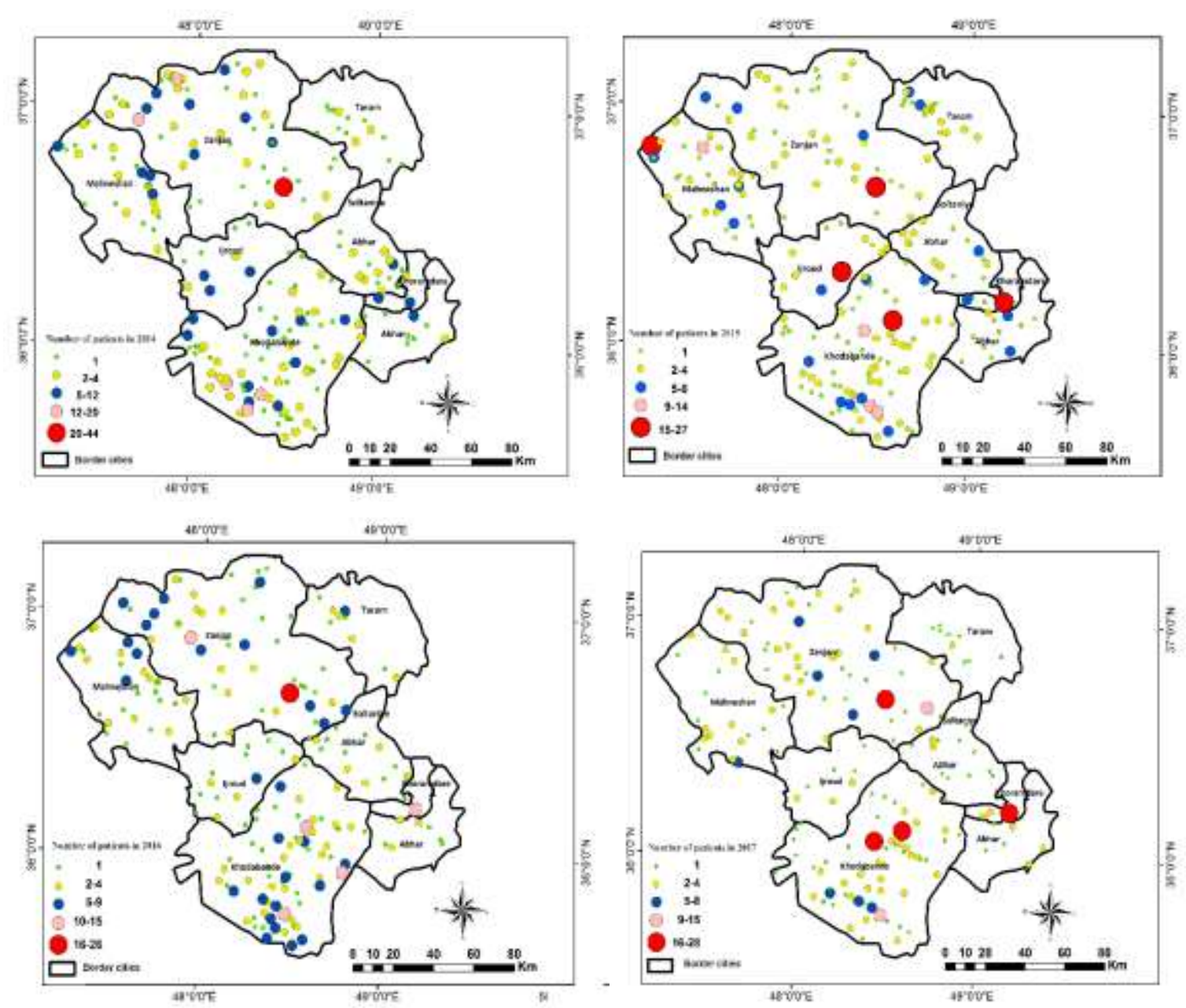

Figure 1. Spatial distribution of brucellosis incidence risk by time from 2012 to 2017

Spatial analysis (spatial variations) indicated the fact that the incidence of the disease in different cities of the province in urban and rural areas grew significantly. As can be seen in Table 1, Khodabandeh city (which had the highest number of sick people, with 162 cases in 2012) had a significant increase to 227 cases in 2014 (14\%) and a decrease to 162 cases in 2017 (83\%). In Zanjan city, there were 46 sick cases in 2012, which increased to 177 cases in 2014 (284\%) and then decreased to 142 cases in 2017 (119\%). In Mahneshan, there were 13 sick cases in 2012, which increased to 107 in 2015 (238\%) and then decreased to 46 cases in 2017 (70\%). Moreover, in Abhar, there were seven sick cases in 2012, which increased to 46 cases in 2015 $(576 \%)$ and then decreased to 15 cases in 2017 (46\%). Also, in other cities of the province, an increased number of infected patients with brucellosis was seen after 2013 (Tables 1 and 2).

A temporal (seasonal) trend analysis demonstrated the significant role of unpasteurized dairy products and livestock vaccination. It also showed that, from 2012 to 2017, the incidence of brucellosis in spring and summer was higher than in other seasons; thereafter, the incidence peak was witnessed in June, July, and August (Table 2).

\section{Discussion}

Considering the temporal and spatial aspects of brucellosis incidence, this study aimed to identify highrisk areas and determine the effectiveness of current brucellosis control programs using Moran's Local methods. We examined 2,829 cases of human brucellosis, prepared by the Infectious Diseases Department of the Ministry of Health, Treatment, and Medical Education in the study. The temporal and spatial model revealed the evolution of the disease, as it increased in some regions over the six-year study period. It also revealed an increase in brucellosis incidence in spring and summer when compared to other seasons.

According to research done by Pakzad et al., the incidence of brucellosis gradually increased from the early spring to the midsummer and then dropped and reached its lowest point in the early winter (3). According to Rezamirnejad et al., a pronounced seasonal fluctuation shows that the number of cases in spring and summer was more than those in autumn and winter (18). In Hashtarkhani et al.'s study, the incidence of the disease peaked from May to September (19).

Journal of Advances in Medical and Biomedical Research 
In a study done by Seyedalizadeh et al., the disease rate increased in the warmer months of the year (i.e., during spring and summer), and it reached its peak in July (20). In Ahmadkhani et al. 's study, the disease prevalence was on an upward trend since February and reached its peak in June before dropping at the end of the year. Similar seasonal patterns have also been observed in other studies. On the other hand, the results show that the incidence of the disease is positively correlated with temperature and evaporation and negatively correlated with precipitation (21).

In a study conducted by Mohammadi et al., in Zanjan province, the correlation between temperature and the number of patients with brucellosis was found to be $13 \%$, the correlation between humidity and the number of patients was found to be $3 \%$, the correlation between rainfall and the number of patients was found to be $5 \%$, and the correlation between wind and the number of cases was found to be $9 \%$ (22). Also, in a study by Seyedalizadeh et al., there was a correlation between the incidence of the disease and temperature and altitude (20). This could explain the increased number of patients in spring and summer.

\section{Conclusion}

In general, according to our results, controlling brucellosis in Zanjan province requires reviewing and designing a dynamic control program with the additional coordination of relevant institutions and organizations.

To identify high-risk periods and areas, the use of spatial and temporal analysis methods is necessary for future control programs as a starting point for the implementation of desired programs and avoiding waste of resources.

It is impossible to examine all people infected with the disease regarding private doctors (prescribing outside the clinic or hospital) and diagnostic errors. Another limitation that may have influenced the research results is the lack of an accurate and thorough registration of the data.

\section{Acknowledgments}

This paper is dedicated to the memory of Professor Soghrat Faghihzadeh. This work had the ethics code IR.ZUMS.REC.1396.311 and was supported by the grant A-11-724-7 of Zanjan University of Medical Sciences. The authors are grateful to the staff of the Health Deputy Department of Zanjan University of Medical Sciences for their work, suggestions, and data gathering that have led to significant improvement of this manuscript.

\section{Conflict of Interest}

Authors declared no conflict of interest.

\section{References}

1. Dehghan A, Sadeghian M, Jafarnejad A. Epidemiologic survey of Brucellosis in Fasa during 2009-2017. Mashhad Univ Med Sci. 2019;62(2):1449-55.

2. Liang $\mathrm{P}$, Zhao Y, Zhao J, Pan D, Guo Z. The spatiotemporal distribution of human brucellosis in mainland China from 2007-2016. BMC Infect Dis. 2020;20(1):249. [DOI:10.1186/s12879020-4946-7]

3. Pakzad R, Pakzad I, Safiri S, et al. Spatiotemporal analysis of brucellosis incidence in Iran from 2011 to 2014 using GIS. Int J Infect Dis. 2018;67:129-36. [DOI:10.1016/i.ijid.2017.10.017]

4. Boxer P, Drawve G, Caplan JM. Neighborhood violent crime and academic performance: a geospatial analysis. Am J Communit Psychol. 2020; 65(3,4):343-52 [DOI:10.1002/ajcp.12417]

5. Zhao C, Yang Y, Wu S, et al. Search trends and prediction of human brucellosis using Baidu index data from 2011 to 2018 in China. Scientific Reports. 2020;10(1):5896. [DOI:10.1038/s41598-020-62517-7]

6. Jafari-Koshki T, Arsang-Jang S, Mahaki B. Bladder cancer in Iran: Geographical distribution and risk factors. Int J Cancer Manag. 2017;10(2) [DOI:10.5812/ijcp.5610]

7. Nyadanu SD, Pereira G, Nawumbeni DN, Adampah T. Geo-visual integration of health outcomes and risk factors using excess risk and conditioned choropleth maps: a case study of malaria incidence and sociodemographic determinants in Ghana. BMC Pub Health. 2019;19(1):514. [DOI:10.1186/s12889-0196816-z]

8. Roberson S, Dawit R, Moore J, Odoi A. An exploratory investigation of geographic disparities of stroke prevalence in Florida using circular and flexible spatial scan statistics. .Plos One 2019;14(8):e0218708. [DOI:10.1371/journal.pone.0218708]

9. Cheung YTD, Spittal MJ, Williamson MK, Tung SJ, Pirkis J. Application of scan statistics to detect suicide clusters in Australia. PLOS ONE. 2013;8(1):e54168. [DOI:10.1371/journal.pone.0054168]

10. Ozdenerol E, Williams BL, Kang SY, Magsumbol MS. Comparison of spatial scan statistic and spatial filtering in estimating low birth weight clusters. Int $J$ Health Geogr. 2005;4:19 [DOI:10.1186/1476-072X-4-19]

11. Jafari-Koshki T, Arsang-Jang S, Raei M. Applying spatiotemporal models to study risk of 
smear-positive tuberculosis in Iran, 2001-2012. Int J Tuberc Lung Dis. 2015;19(4):469-74. [DOI:10.5588/ijtld.14.0459]

12. Rastaghi S, Jafari-Koshki T, Mahaki B. Application of Bayesian multilevel space-time models to study relative risk of esophageal cancer in Iran 2005-2007 at a county level. Asian Pac J Cancer Prev. 2015;16(14):5787-92. [DOI:10.7314/APJCP.2015.16.14.5787]

13. Hastie TJ, Tibshirani RJJFCP. Generalized additive models, vol. 43 Boca Raton. 1990.

14. Diggle PJ, Moraga P, Rowlingson B, Taylor BMJSS. Spatial and spatio-temporal logGaussian cox processes: extending the geostatistical paradigm.Stat Sci. 2013;28(4):542-63. [DOI:10.1214/13-STS441]

15. Gabriel EJM, Probability CiA. Estimating second-order characteristics of inhomogeneous spatio-temporal point processes. Statistic Theory. 2014;16(2):411-31 [DOI:10.1007/s11009-013-9358-3]

16. Ripley BDJJoap. The second-order analysis of stationary point processes. J Applied Prob 1976;13(2):255-66. [DOI:10.2307/3212829]

17. Tamayo-Uria I, Mateu J, Diggle PJJSS. Modelling of the spatio-temporal distribution of rat sightings in an urban environment. Spatial Statistics. 2014;9:192-206 [DOI:10.1016/j.spasta.2014.03.005]

18. Mirnejad R, Jazi FM, Mostafaei S, Sedighi M. Molecular investigation of virulence factors of Brucella melitensis and Brucella abortus strains isolated from clinical and non-clinical samples. Microb Pathogen. 2017;109:8-14. [DOI:10.1016/j.micpath.2017.05.019]

19. Hashtarkhani S, Akbari M, Jarahi L, Etminani K. Epidemiological characteristics and trend of incidence of human brucellosis in Razavi Khorasan province. Mashhad Univ Med Sci. 2015;58(9):531-8.

20. Seyedalizadeh N, Alesheikh A, Ahmadkhani M. Spatio-statistical modeling of human brucellosis using environmental parameters: A case study of Northern Iran. Int Arch Photogramm Remote Sens.2019; XLII-4/W18: 969-973 [DOI:10.5194/isprs-archives-XLII-4-W18-9692019]

21. Ahmadkhani M, Alesheikh AAJAPJoTD. Spacetime analysis of human brucellosis considering environmental factors in Iran. Asian Pacific J Trop Dis.2017;7(5):257-65. [DOI:10.12980/apjtd.7.2017D6-353]

22. Mohammadi N, Kamali K, Abedini Y, Ahadnejad M, Azari M.Medical meteorology; the relationship between meteorological parameters (Humidity, Rainfall, Wind, and Temperature) and brucellosis in Zanjan province. J Hum Environ Health Promot. 2016;1(3):149-58. [DOI:10.29252/ihehp.1.3.149]

\section{How to Cite This Article:}

Rostame Z, Faghihzadeh S, Taghilou B, Khosravi Y. Determining the Incidence Rate and Risk Factors of Brucellosis in Zanjan Province (Iran) from 2012 to 2017: A Spatiotemporal Analysis. J Adv Med Biomed Res. 2020; 28 (130) :247-252

Download citation:

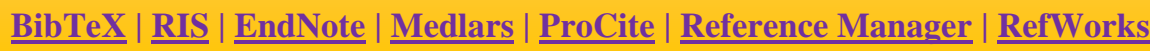

\section{Send citation to:}

9. Mendeley 2 Zotero 9 Marka $\underline{\text { RefWorks }}$ 